\title{
Developmental trends in item recognition following a verbal discrimination study trial
}

\author{
ROBERT M. YADRICK and GAYLA L. DODD \\ Columbia College, Columbia, Missouri 65201 \\ and \\ DONALD H. KAUSLER \\ University of Missouri, Columbia, Missouri 65201
}

\begin{abstract}
Age-related changes in the processes mediating verbal discrimination learning were investigated by a procedure in which right, wrong, and new items were tested individually for oldness after a single study trial on right-wrong pairs. Sixth-grade children displayed higher hit rates than fourth-grade children for both right and wrong items, suggesting that increasing age is accompanied by both increasing rehearsal responses to right items and increasing perceptual responses to wrong items. The increase with age in responses to wrong items serves to compensate for the gain in responses to right items, thus accounting for the absence of pronounced age increments in verbal discrimination learning proficiency.
\end{abstract}

Most verbal learning tasks reflect increments in learning proficiency with increasing age through at least the sixth-grade level. This developmental trend has been noted in free recall learning (e.g., Halpern, 1974), serial learning (e.g., Posnansky, 1974), and paired-associate learning (e.g., Jensen \& Rohwer, 1965). Age-related increments in the rate of rehearsal responses (Kellas, McCauley, \& McFarland, 1975) may account for these findings. However, a possible exception to this positive covariation between age and learning proficiency may be found in verbal discrimination learning tasks. Barch and Whalen (Note 1) found no overall age effect with fourth, fifth, and sixth graders, while Barch, Lippman, and Whalen (Note 2) discovered only a modest superiority for sixth graders relative to fourth graders. Conversely, Deichmann, Speltz, and Kausler (1971) reported superior learning for fourth graders relative to sixth graders in one experiment, and for third graders relative to sixth graders in another experiment.

According to Ekstrand, Wallace, and Underwood's (1966) frequency theory, greater numbers of responsebased frequency units accrue to right item members of pairs than to wrong item members, thereby producing intrapair cues for selecting the right item members. The disparity between right and wrong frequency units is presumed to result from the fact that wrong items

This research was supported by National Science Foundation Grant BMS75-05007 awarded to Donald H. Kausler. We wish to thank Sister Frances Lalor, principal of the Columbia Catholic School, for arranging the availability of the subjects. Requests for reprints should be sent to Donald H. Kausler, Department of Psychology, McAlester Hall, University of Missouri, Columbia, Missouri 65201. largely receive only perceptual responses, whereas right items receive both perceptual and rehearsal responses. Assuming that rehearsal responses covary positively with age, the findings which indicate little or no age-related increment in verbal discrimination learning proficiency seem paradoxical.

A Weber's law principle incorporated by Ekstrand et al. (1966) in their frequency theory can perhaps account for this paradox. This principle states that subjective disparity in frequency units between intrapair right and wrong items is inversely related to the absolute amount of preexperimental item familiarity. If increasing age provides increasing familiarity with words, right item discriminability should decrease as intrapair familiarity increases. The resulting decrease in discriminability could mitigate the benefits of greater rehearsal rates of older children.

However, an alternative explanation is that older children simply direct more attention to the wrong items of pairs than do younger children. The resulting increase in perceptual responses to wrong items would mitigate the presumed benefits of greater rehearsal directed at right items by older children. Thus, the intrapair disparity between right and wrong items would remain roughly invariant with increasing age, even though the absolute number of responses to items per se increases with age. If this interpretation is correct, older children would learn more individual wrong items, as well as right items, than younger children. Unfortunately, little may be learned from a standard verbal discrimination task about the extent of individual item learning.

The present study attempted to further our understanding of age-related changes in verbal discrimination learning by examining the acquisition of individual 
item information. Individual item learning was tested for fourth- and sixth-grade children by means of a methodological paradigm introduced by Kausler, Pavur, and Yadrick (1975). In this paradigm, a standard study trial on a verbal discrimination list is followed by a single item, rather than a paired item, recognition test. The item recognition test list includes all old right and wrong items from the study list, interspersed with new items. The subject's task is to identify the oldness or newness of each test item. Kausler et al. (1975) conceptualized item recognition in terms of signal detection concepts. Briefly, during a single verbal discrimination study trial, variability in frequency units accruing to both right and wrong items is assumed to result in the generation of partially overlapping distributions of frequency units for wrong and right items. Further, the mean of the right item distribution is presumed to exceed the mean of the wrong item distribution. In addition, the mean of the noise distribution formed by new test items is assumed to fall below that of the wrong item distribution. Old-new decisions are made with respect to a criterion value set at a relatively low level of frequency units. Any item whose frequency value exceeds this criterion is identified as old, and any item whose frequency value lies below this criterion is identified as new.

If older children do rehearse right items more than do younger children, the proportion of right items exceeding the criterion should also be greater for older children. Similarly, if older children attend more to wrong items than do younger children, the proportion of wrong items exceeding the criterion should also be greater for older children. Consequently, the hit rate for identifying the oldness of both right and wrong items should be greater for sixth-grade children than for fourth-grade children.

\section{METHOD}

\section{Subjects}

The subjects were 18 fourth-grade children and 21 sixthgrade children, all of whom attended parochial schools in Columbia, Missouri, and all of whom were participating for the first time in a learning experiment. Approximately equal numbers of each sex participated at each grade level. The subjects in each grade group were divided randomly into three equalsized subgroups that received the three different experimental lists described later.

\section{General Description, Design, and Materials}

An initial pool of 56 items was formed by selecting words from a reading text. All words in this pool were, in the estimation of teachers at the school, within the reading repertory of all subjects employed in the present experiment. All words in the pool were AA in the Thorndike-Lorge (1944) frequency count. Care was taken to minimize associative relatedness between any two items.

Six items from the pool were randomly selected to form three practice right-wrong pairs. A practice session with these three pairs, together with the instructions given, served to imply to all subjects that the main task would follow the format of a standard verbal discrimination learning task.
Following the practice session, all subjects received a single study trial on an experimental list of paired right and wrong items, with the expectation of receiving a subsequent paired item test list. Thirty items from the initial pool were used in constructing three experimental lists. Each list contained 10 right-wrong pairs, with the remaining 10 words reserved for use as new test items in the subsequent recognition test. Items were rotated systematically such that each of the 30 experimental items was used once as a right item, once as a wrong item, and once as a new item across the three different lists.

In addition to the 10 experimental right-wrong pairs, 4 additional pairs were rotated through the first two and last two positions in the study list sequence. This was done to control for possible primacy and recency effects.

After this single trial, all subjects were informed that their recognition would be tested in a manner different from that of the previous practice session. That is, they were told that they would be tested for the recognition of individual items. They were also told that the items could be old and previously right, old and previously wrong, or new. To assure that these instructions were understood, another short practice session was conducted, this time by presenting singly items which were previously right or wrong members of primacy-recency. pairs or new items from the initial pool that had been reserved for this purpose. This practice list consisted of six items (two right, two wrong, and two new). Finally, all subjects received a 40-item recognition test. The test list had an identical composition for each subject. It consisted of the complete 30 -item experimental pool, plus 10 additional filler items reserved for this purpose from the initial pool.

\section{Procedure}

Subjects were tested individually. For both practice and experimental study phases, pairs were presented on slides using a Carousel projector. Items were arranged in a top-bottom spatial order, with half of the experimental pairs having the right item on top and half on bottom. The right item of each pair was identified by being underlined.

At the start of the session, the task was explained as involving a memory test in which subjects try to remember the right member of each one on a number of pairs. Practice pairs were then presented at a self-paced rate. The experimental study list followed. The exposure was $6 \mathrm{sec} /$ pair. The subjects had been informed that their earlier list was only for practice and that this was not the "real" list upon which they should concentrate their efforts. They were also informed in advance that their study time per pair would be limited. A different serial ordering of pairs was given to each subject, with the exception of the primacy-recency control pairs. Following the study trial, the nature of the actual recognition task was explained, accompanied by the previously described practice test. Subjects then received the 40-item experimental list presented at a 15 -sec rate via a Carousel projector, and they recorded their old-new decisions on an answer sheet.

\section{RESULTS AND DISCUSSION}

In the earlier studies on item recognition with young adult subjects (Kausler et al., 1975; Kausler \& Yadrick, 1977), individual words served as data points or "subjects" for all statistical analyses. The same procedure was employed in the present analyses. Consequently, both grade level and item function (i.e., prior right, prior wrong, and new) became within-subject variables for all analyses of variance in that each of the 30 experimental words served in all functions for each grade level. The analyses of variance reported here were 
conducted on arc-sine transformations of the various proportions serving as data points. The results of comparable analyses of the same data without transformation closely approximated those found with the transformations.

The proportion of subjects in each grade identifying a test item as old was determined for each word in its separate roles as an old prior right item, an old prior wrong item, and a new test item. Mean hit rates for prior right and wrong roles, together with the mean false alarm rate for the new item role, were then computed for the total set of 30 words at each grade level.

For right items the mean and standard deviation were .772 and .167 for the fourth graders and .843 and .132 for sixth graders; for wrong items the comparable statistics were .489 and .243 for fourth graders and .576 and .239 for sixth graders. Thus, the hit rate for prior right items was considerably greater than the hit rate for prior wrong items at each grade level, and the hit rate for both kinds of items was greater for sixth graders than for fourth graders. These hit rates were analyzed by a 2 by 2 within-subject analysis of variance, with study list function (right or wrong) and grade level as the variables. The analysis yielded significant main effects $(\mathrm{MSe}=.02)$ for item function $[\mathrm{F}(1,87)=61.00$, $\mathrm{p}<.001]$ and grade level $[\mathrm{F}(1,87)=5.00, \mathrm{p}<.05]$, but no significant interaction $[F(1,87)<1]$. For false alarms to new items the mean and standard deviation were .328 and .242 for fourth graders and .362 and .211 for sixth graders. An analysis of variance revealed that the effect of grade level was clearly not significant $[\mathrm{F}(1,29)=1.10, \mathrm{MSe}=.02]$.

The greater hit rate for prior right items than for prior wrong items replicates the results found with young adult subjects (e.g., Kausler et al., 1975; Kausler \& Yadrick, 1977) and is in agreement with the results predicted by the signal detection version of frequency theory. That is, right items accrue more responses than wrong items and, therefore, have a greater proportion of their total number exceeding the criterion for mediating old-new decisions. The greater overall hit rate for sixth graders than for fourth graders, regardless of item function, suggests that increasing age is accompanied by an increasing response rate that includes perceptual responses to wrong items as well as rehearsal responses to right items. The implication, of course, is that it is this increased perceptual responding to wrong items with increasing age that accounts for the previously reported absence of a pronounced age-related increment in verbal discrimination learning proficiency. That is, the advantage for intrapair discriminations gained by older children through their increased rehearsal responses to right items is largely mitigated by their increased perceptual responding to wrong items.
Finally, of general interest is the comparison between the present hit rates and those found with young adults after a single study trial. For example, Kausler and Yadrick (1977) reported hit rates of .850 and .664 for right and wrong items, respectively, and a false alarm rate of .306 with their young adult subjects. Although sixth-grade subjects show a comparable hit rate for right items, they are well below the young adult level for wrong items. Increasing age beyond the sixth-grade level is presumably accompanied by increasing attention directed at wrong items during practice on a verbal discrimination learning task, at least during the early stages of practice.

\section{REFERENCE NOTES}

1. Barch, A. M., \& Whalen, C. Intrapair relations in verbal discrimination learning: Confirmation of paradoxical results. Paper read at the meeting of the American Psychological Association, Miami Beach, September 1970.

2. Barch, A. M., Lippman, M., \& Whalen, S. Intrapair relations in verbal discrimination learning. Paper read at the meeting of the Midwestern Psychological Association, Chicago, May 1967.

\section{REFERENCES}

Deichmann, J. W., Speltz, M. B., \& Kausler, D. H. Developmental trends in the intentional and incidental learning components of a verbal discrimination task. Journal of Experimental Child Psychology, 1971, 11, 21-34.

Ekstrand, B. R., Wallace, W. P., \& Underwood, B. J. A frequency theory of verbal discrimination learning. Psychological Review, 1966, 73, 566-578.

HALPER, M. S. Developmental changes in the recall and recognition of categorized word lists. Child Development, 1974, 45, 144-151.

Jensen, A. R., \& Rohwer, W. D., JR. Syntactical mediation of serial and paired-associate learning as a function of age. Child Development, 1965, 36, 601-608.

Kausler, D. H., Pavur, E. J., JR., \& YAdrick, R. M. Single-item recognition following a verbal discrimination study trial. Memory \& Cognition, 1975, 3, 135-139.

KAUSLER, D. H., \& YADRICK, R. M. Item identifications following varying study trials on a multiple-item recognition learning task. Journal of Experimental Psychology: Human Learning and Memory, 1977, 3, 203-210.

Kellas, G., McCauley, C., \& McFarland, C. E., JR. Developmental aspects of storage and retrieval. Journal of Experimental Child Psychology, 1975, 19, 51-62.

Posnansky, C. J. An investigation of serial learning and retention processes in children. Journal of Experimental Child Psychology, 1974. 18, 127-148.

THORNDIKE, E. L., \& LORGE, I. The teacher's word book of 30,000 words. New York: Teachers College Press, Columbia University, 1944.

(Received for publication March 3, 1977.) 